\title{
Patterns of engagement between GPs and adolescents presenting with psychological difficulties:
}

\author{
a qualitative study
}

\begin{abstract}
\section{Background}

Psychological difficulties are common in adolescence with general practice attendees having higher rates than reported in community surveys. Yet GP identification of common mental health problems in this age group is limited. Anxiety and uncertainty around professional practice have been found among GPs and they vary in their degree of engagement with adolescents presenting with psychological difficulties.
\end{abstract}

\section{Aim}

To explore which factors influence the degree of GP engagement.

\section{Design and setting}

Qualitative study based in 18 practices in the north east of England. The practices recruited included rural, urban, and mixed populations of patients predominantly living in socioeconomically disadvantaged communities.

\section{Method}

Theoretical sampling was used to guide recruitment of GP participants continuing until theoretical saturation was reached. Data were analysed using the constant comparative method of grounded theory and situational analysis.

\section{Results}

In total 19 GPs were recruited: 10 were

female, the age range was $29-59$ years, with a modal range of $40-49$ years. The participants collectively described a sense of their professional competence being challenged, yet reacted with varying degrees of engagement. Three themes appeared to shape a GP's response: performance in the clinical encounter; view of adolescents and their health needs; and the GP's own preferred epistemological framework

\section{Conclusion}

The findings suggest that better patterns of engagement between GPs and adolescents are supported by medical education which includes input and feedback from adolescents; education about the science and psychology of adolescence; more effective working across disciplinary boundaries; and recognition of the importance of addressing psychological difficulties early.

\section{Keywords}

adolescent psychological difficulties; GP consultation style; youth mental health.

\section{INTRODUCTION}

Mental disorders contribute the largest disease burden in young people globally, with estimated rates of one in four. Nationally, the data sets are both limited and aggregated and estimate that $10 \%$ of $<18$-year olds have a clinically diagnosable mental health disorder. ${ }^{2}$ Regular surveys have been called for by the Chief Medical Officer to capture trends which are believed to be increasing. ${ }^{3}$ Definitions for young people' vary. This article focuses on adolescents who are defined as being between 10-19 years of age. ${ }^{4}$

While mental health problems in adolescence are common, they are often not detected in primary care. This is despite findings that adolescents presenting to GPs are a group found to have higher levels of psychological problems with a prevalence of $25-40 \% .^{5-7}$ Teenagers consult their GP on average twice a year, with rates increasing for older female teenagers.,9

International data suggest delays of 5-15 years for diagnoses are typical for common mental health disorders manifesting in the teenage years. ${ }^{10}$ Undetected poor mental health has consequences that are wide ranging and detrimental, including negatively impacting on academic achievement and employment prospects, social, and familial relationships, and an increased risk of health-compromising behaviours.

Investigating GPs' low rate of detection of mental health problems has tended to

JH Roberts, PhD, FRCGP, RCGP Clinical Champion for Youth Mental Health, Northern Strategic Clinical Network primary care mental health lead; $\mathbf{A}$ Crosland, PhD, professor of nursing: J Fulton, $\mathrm{PhD}$, principal lecturer in health, Faculty of Applied Sciences, University of Sunderland, Sunderland.

\section{Address for correspondence}

Jane Roberts, CIRC, RCGP, 30 Euston Square, focus on 'GP psychiatry training' as the sole strategy for improving recognition, a position which has been criticised for its limited perspective. ${ }^{11}$ Understanding how GPs view and respond to psychological difficulties in adolescence is critical if we are to promote greater involvement by GPs with young people who rarely present with an obvious 'mental health problem' 5 but typically present with messy scenarios often involving conflict (family or peers), problems in school, or risky behaviour. Quantitative studies report low self-ratings of GP confidence when talking to adolescents about these topics. ${ }^{12,13}$ Martinez et al ${ }^{14}$ report a reluctance to both identify and respond to signs of suspected psychological problems and Haller and colleagues suggest GPs are influenced by a young person's own level of emotional literacy. ${ }^{7}$

The existing qualitative evidence is scant. Illiffe and colleagues report GPs being 'uncomfortable' diagnosing depression, ${ }^{15}$ and not wanting 'to medicalise psychological distress' ${ }^{16}$

This article presents a qualitative study exploring GPs' experiences and perceptions of consulting with adolescents who present with psychological difficulties. It builds on an earlier first level of analysis which concluded that professional anxiety and uncertainty about practice dominate consultations in this arena. ${ }^{17}$ The second level of analysis presented here explores the factors that influence patterns of GP engagement.
London NW1 2FB.

E-mail: jane.robertsarcgp.org.uk

Submitted: 19 December 2013; Editor's response:

1 February 2014; final acceptance: 3 March 2014. (CBritish Journal of General Practice

This is the full-length article (published online 28 Apr 2014) of an abridged version published in print. Cite this article as: Br J Gen Pract 2014; DOI: 10.3399/bjgp14X679660 


\section{How this fits in}

Psychological problems are common in adolescents but not often detected by GPs. GPs are reluctant to medicalise emotional and behavioural problems and hesitant to initiate consultations to explore these areas. Anxiety and uncertainty dominate practice in this clinical area but GPs vary in their response to professional uncertainty. This research found that the GP participants collectively described a sense of their professional competence being challenged yet reacted with varying degrees of engagement. Three themes appeared to shape a GP's response: performance in the clinical encounter; view of adolescents and their health needs; and the GP's own preferred epistemological framework.

\section{METHOD}

\section{Study design}

The study took place in the north east of England in 18 general practices based in

\section{Table 1. Demographics of study participants}

\begin{tabular}{|c|c|c|c|c|c|}
\hline $\begin{array}{l}\text { Participant } \\
\text { ID }\end{array}$ & Sex & $\begin{array}{l}\text { Age, } \\
\text { years }\end{array}$ & $\begin{array}{c}\text { Salaried or } \\
\text { partner }\end{array}$ & $\begin{array}{l}\text { Practice } \\
\text { descriptor }\end{array}$ & $\begin{array}{c}\text { Additional professional } \\
\text { experience }\end{array}$ \\
\hline 01 & $\mathrm{~F}$ & $50-59$ & S & Semi-rural, deprived & $\begin{array}{c}\text { GP } \\
\text { Postgraduate education }\end{array}$ \\
\hline 02 & M & $50-59$ & S & Urban, deprived & $\begin{array}{l}\text { Addiction medicine } \\
\text { in primary care }\end{array}$ \\
\hline 03 & $\mathrm{~F}$ & $50-59$ & $P$ & $\begin{array}{l}\text { Urban, deprived; wealthy } \\
\text { student population }\end{array}$ & $\begin{array}{l}\text { Former associate } \\
\text { specialist in CAMHS }\end{array}$ \\
\hline 04 & $\mathrm{~F}$ & $40-49$ & S & Semi-rural, deprived & $\begin{array}{l}\text { Mental health lead } \\
\text { for a PCT }\end{array}$ \\
\hline 05 & $\mathrm{~F}$ & $20-29$ & S & Urban, deprived & \\
\hline 06 & M & $40-49$ & $\mathrm{P} S \mathrm{~S}$ & Semi-rural, largely affluent & \\
\hline 07 & M & $40-49$ & $P$ & Semi-rural, mixed & Child protection lead for a PCT \\
\hline 08 & $\mathrm{~F}$ & $30-39$ & S & Semi-rural, mixed & \\
\hline 09 & M & $50-59$ & $P$ & Semi-rural, mixed & $\begin{array}{c}\text { GP lead for } \\
\text { teen drop-in' clinic }\end{array}$ \\
\hline 10 & M & $40-49$ & $P$ & Urban, deprived & $\begin{array}{l}\text { Mental health and } \\
\text { child protection lead for } \\
\text { a PCT. Substance misuse }\end{array}$ \\
\hline 11 & $\mathrm{~F}$ & $20-29$ & S & Urban, deprived & \\
\hline 12 & M & $30-39$ & $\mathrm{~S}$ & $\begin{array}{c}\text { Semi-rural } \\
\text { mixed: largely affluent }\end{array}$ & \\
\hline 13 & $\mathrm{~F}$ & $30-39$ & $S$ & Urban, deprived & \\
\hline 14 & M & $40-49$ & $P$ & Urban, deprived & \\
\hline 15 & M & $40-49$ & $P$ & Semi-rural, mixed & \\
\hline 16 & $\mathrm{~F}$ & $20-29$ & $S$ & Urban, deprived & \\
\hline 17 & M & $30-39$ & S & Urban, deprived & \\
\hline 18 & $\mathrm{~F}$ & $40-49$ & $P$ & Semi-rural, affluent & \\
\hline 19 & $\mathrm{~F}$ & $50-59$ & $P$ & Semi-rural, mixed & Child health lead \\
\hline
\end{tabular}

$F=$ female. $M=$ male urban, rural, and semi-rural communities serving predominantly socioeconomically disadvantaged patients. Data were collected between January 2010 and May 2011.

\section{Participants}

Nineteen GPs were recruited using theoretical sampling, which identifies participants on the basis of their demographic characteristics and ability to contribute to disproving or confirming emerging themes, including inviting 'outliers' who might challenge the developing themes. For demographic details of the sample see Table 1. Further details of the recruitment process are reported elsewhere. ${ }^{17}$

\section{Data collection and analysis}

GPs were interviewed individually in a location of their choice by one author la GP) using interview topic guides (based on the literature) (Appendix 1). The interviews lasted between 50-75 minutes and were audiorecorded and transcribed verbatim with consent.

The transcripts were coded and analysed using the constant comparative method of grounded theory, 18,19 and iteratively commented on. To compliment grounded theory situational analysis was used. ${ }^{20}$ This is a cartographic approach which uses 'maps' to explore the contextual background, the key influences and current accepted 'discourses' in the topic of inquiry (maps are available on request from the authors).

Recruitment of GP participants continued until theoretical saturation had been reached.

The concept of 'GP engagement' emerged from the multilevel analysis, with GPs found occupying a spectrum from high to low levels of GP involvement with adolescent psychological difficulties.

\section{RESULTS}

Three main themes emerged which appear to explain differences in the level of GP engagement.

These three themes, presented in detail below, form the axes of a conceptual model which summarises the third and final level of analysis and is described in a companion article. ${ }^{21}$

The three themes were GP performance in the clinical encounter; GPs view of adolescents and perception of their health needs; and GPs' preferred epistemological framework.

\section{GP performance in the clinical encounter} Clinical consultations in this arena present a number of challenges for GPs. 


\section{Box 1. GPs' performance in the clinical encounter (with adolescents)}

I think they are a difficult group, ... partly because of the way / suppose things present and the way they access us and the way they relate to the problems, that can be difficult and all the issues about confidentiality and parents being present or not present comes into it. And, there is a feeling that because they're, they are young people there should be lots of resources there for them and there aren't I think a lot of the time so not knowing what to do is a bit of a theme really. ' $07 ; \mathrm{M} ; 40-49$; partner [P])

I suppose the reason you are doing this study is because it's a funny area isn't it - there a lot of black clouds hanging over it. It's possibly one where people think "Oh here we go again, how am I going to do this? I know, I'll send them to CAMHS"...' (11; F; 20-29; salaried [S])

\section{The triadic consult}

you tend to get the whole family in the room and it's all quite tense and everyone's quite erm, stressed basically ... and with an adult with depression I might start them on treatment and see them again in 2 weeks or something, but with teenagers, because we can't prescribe, or it is not advised to prescribe, it kind of feels to me like we have to take action now. '(17; M; 30-39; S)

You have two people to mirror the body language and they have different agendas so its inherently difficult I think. The parents always have a fixed agenda, the child more often than not at that age is not very forthcoming and sometimes it is difficult to tease out what is important for them ...' $(12 ; \mathrm{M} ; 30-39 ; \mathrm{S})$

When I was a younger GP, I used to feel quite irritated when a young person brought a friend in with them, like it was a kind of a spectator sport.' (09; M; 50-59; P)

I think I find it confusing to know what I am actually doing. I think often in that situation the parent wants to consult with me, with the youngster present and then the parents are interpreting for the young person what's going on, and so then you're deciding about what actually is going on ... sometimes I feel I am put in quite a difficult position by a parent, with them sort of wanting to collude with me, almost against the person who is actually sitting in the chair ... so that can be a really tricky path ... when everyone is in the room.' $(18 ; \mathrm{F} ;$ 40-49; P)

\section{Box 2. Communicating with adolescents}

Generally consulting with young people, I often find, if I'm being honest probably more difficult than I would expect to find it. I think I probably have this unrealistic view of myself as really sort of approachable and you know still being quite young myself compared to other GPS, you know being able to communicate fairly easily and fairly well with young people, then always very quickly, it becomes apparent that actually no, you are a million miles away from where they are and they don't really relate to you very well at all ... '(08; F; 30-39; S)

I think they are kind of almost quite enjoyable consultations because it is finding out a bit more about them, about the set up at home, or whatever, so I think, I am quite a nosey person actually ... I quite enjoy finding out those kind of, you know how are they getting on at school, what they enjoy doing, this kind of thing, erm, so / don't find it difficult.' (16; F; 20-29; S)

I really don't feel I know the children ... and don't know the family at all, but it's come to a head if you like at the school and so then they feel quite pressured to get things done and get them done quickly or else they might get excluded or whatever, and so, erm, part of me doesn't feel like there's time to get to know them, like, ... I kind of feel I can't kind of say "oh well come back in a month." (17; M; 30-39; S)

Data from the study suggested that GPs consulting with psychologically troubled teenagers often felt a sense of professional disempowerment: stemming from a lack of formal training and education about the clinical topic; problematic access to further help; and lack of clarity about what was expected of the GP.

The triadic consult. Adolescents typically present with a third party, usually a parent or guardian but can also include a friend or chosen family member. Both arrangements had the potential to create tension and were frequently described by participants as professionally challenging, especially when a young person attends unwillingly (Box 1, 11; F; 20-29; S).

Communicating with adolescents. A recurring theme among the participants was the challenge of talking with teenagers. A range of opinions were expressed, from a view that only services designed to work with younger patients were qualified to communicate effectively with adolescents to a view that life experiences, such as one's own adolescence or being a parent, facilitated a more natural approach which made communication between GP and patient easier. No participant reported any formal educational preparation for talking to young people.

The variability and unpredictability of adolescent behaviour was cited as problematic, dissuading GPs from engaging as the situation could change from day to day.

Uncertainty about adolescent mental health and limited contact with secondary care colleagues compromised a desire to be more engaged with psychological presentations; a position made worse by often feeling direct action was expected by families (Box 2, 17; M; 30-39; S)

The potential that a presentation might suggest a history of abuse, either present or historical, was an additional source of professional anxiety.

Responding to cultural clashes. In the context of this study 'cultural clashes' refers to GPs, parents, and adolescents operating within different norms and expectations of social behaviour. The interviews revealed that consultations invited potential 'clashes' around norms for alcohol drinking, drug misuse, use of digital media, and relationships between teenagers and parents; with GPs trying to navigate their way through the cultural context in order to decide 'what is normal' in this situation and how best to proceed, without a clear steer (Box 3, 06; M; 40-49; P).

\section{GPs' views of adolescents and perception of their health needs}

Adolescents as 'different' or seen to be on a life journey. A key influence on patterns of engagement centred on whether GPs saw teenagers as 'a group apart' or as patients on a life's journey with particular needs and concerns, relevant to their stage in life. The view that adolescents are 'different' distanced GPs from viewing their health needs and concerns with compassion and was a barrier to engagement. In contrast 


\section{Box 3. Responding to 'cultural clashes'}

she looked about 17 but she was 13, and she came on her own two or three times and talked about her father's anger; they live on the council estate round the corner and the father is of gypsy stock... she came to see me and she was very upset about her relationship with her father. She was refusing to go to school and he was shouting at her and dragging her out of bed to go to school, and I had all sorts of mixed feelings about "well she is not telling me he has hit her". ... And he ended up coming to see me, late on a Friday night and being very angry and I felt a bit scared, and think, I had nothing to feel scared about - he acted like a slightly angry gypsy would act. He didn't hit me, he shouted at me, told me "I was useless, it was normal behaviour" and what would I do if I had a daughter like his?... And all those thoughts had been through my mind previously and I had the embarrassing feeling of he was right.' (06; M; 40-49; P)

and his mum brought him in and just sort of dumped him, like exhibit $A$... but then he started talking about how he feels, fantastic, so I asked mum to go out and erm, we were having a chat and he just opened up, amazing ... and he said he felt angry all the time and I asked him about drugs and alcohol cos he seemed like quite an old 15 and he said "oh yeah, I take some cannabis", I think it was, and he said that his step dad, so the mum's boyfriend had given it to him, so there was loads of issues going on and he really opened up .... $(11 ; \mathrm{F} ; 20-29 ; \mathrm{S})$

You might think asking somebody how many beers they have down the pub isn't a problem whereas in actual fact it's very different in reality. ... I think it goes back to the experience and the responses that you've had from people in the past with certain things that you've said to them, you know, asking young person about drinking and drinking excessively - a lot of them will look at you as though you're stupid, why would I be drinking I'm only 17, you know, so yeah I think it's unexpected things sometimes that cause difficulty and may cause difficulty in future because you've now had difficult experience with it and then it plays on your mind and then you worry about it ... . (08; F; 30-39; S)

\section{Box 4. GPs' views of young people and their perception of adolescent health needs}

Adolescents as 'different'

I think they are quite different because they are like in that transition phase from childhood to adulthood and it's different for different people - what is normal for young people? Are they adults or are they a child, or neither, or both ?' $(17 ; \mathrm{M} ; 30-39 ; \mathrm{S})$

It think myself, and probably a lot of other doctors, find that a sullen, sulky, brooding teenager probably one of the most difficult patients to deal with.' $(15 ; \mathrm{M} ; 40-49 ; \mathrm{P})$

I would say that they are a different group in that the communication might be more difficult because it's not a group that's always used to talking to adults about difficult issues, in particular I think for boys. ' $(01 ; \mathrm{F} ; 50-59 ; \mathrm{S}$ )

'Even though the problem may not be a mental health problem that you would normally refer to a psychiatrist, but it's the fact that it's that particular type of age group that they need CAMHS. ' $15 ; \mathrm{M} ; 40-49 ; \mathrm{P})$

\section{Adolescents as seen to be on a life journey}

I suppose also, obviously, it is a difficult time being a teenager with all the life choices; do I want to go uni or don't I? ... Relationships in their lives and just becoming independent. It's a time when I think mental health problems are quite common aren't they? Or at least stress is quite common. ' $(11 ; \mathrm{F} ; 20-29 ; \mathrm{S})$

I think it's easier having kids of your own and knowing their own little foibles and knowing the significance of a yes and no answer that they don't usually mean what they are actually saying. And their expectations are slightly different and time spans and demands tend to be much shortened, you know. They are wanting a response immediately to most things. And also the emotional toll that's on it, you know, even something as simple as acne ... $(14 ; \mathrm{M} ; 40-49 ; \mathrm{P})$

I think they go through a difficult time in their life in terms of hormones and family and are becoming more independent and I can see all of that and those are difficult and challenging times for them as individuals and them as a member of the family and that makes them special. But that's perhaps no different to a woman coming towards the end of her periods and going through menopause and the kids leaving home. $(18 ; \mathrm{F} ; 40-49 ; \mathrm{P})$ their understanding of the asynchronous neurodevelopment in adolescence and of the typical presentations of common mental health conditions in this age group. GPs who displayed a broad understanding of the developmental changes young people experience were much more likely to adopt an empathic approach, and engage with the young person and their story.

Importance of trust in the doctor-patient relationship. An area of consensus concerned the importance of trust in therapeutic relationships between adolescents and their GP. This was considered to be qualitatively different when compared to older patients and stemmed from a position that older patients were more likely to uncritically trust their doctor. In contrast, GPs spoke of 'earning the trust' from teenagers who often needed to 'test' a GP before they were ready to disclose sensitive information.

A 'duty of care'. GPs who viewed young people as being on a life journey were both more likely to speak of their responsibility to adolescents, contrasted with those who saw them as a group apart, and to recognise that their age conferred a certain vulnerability and duty of care which contrasted with older patients.

The importance of responding to need in a timely fashion was also seen as critical with a delayed or lack of response having potentially life-long consequences (Box 5 , 08; F; 30-39; S).

\section{GPs' preferred epistemological \\ framework}

The knowledge frameworks that GPs used to understand illness, disease, and distress were a key influence in shaping a GPs' response to, and degree of engagement with, adolescent psychological difficulties.

The participants occupied a range of epistemological positions along a continuum and although these positions are not fixed, the accounts suggested that most people tend to occupy a favoured position. The continuum has two poles. At one end is the biomedical paradigm and at the other end sits interpretative medicine. The mid position might best be described as the biographical-biological perspective which prioritises the accounts of individual patients within the context of their family and community. This was the most populated position.

GPs who drew on the biomedical paradigm viewed psychological difficulties, regardless of the age of the patient, as a manifestation 


\section{Box 5. Importance of trust in the doctor-patient relationship}

I think confidentiality is an issue for young people, so trust, I think trust is different I almost feel I have to earn it more with young people, whereas with adults they give you that more freely. (01; F; 50-59; S)

'The first time she came was about her acne. The later, it was about 3 months after the death of Princess Diana, and she said "oh by the way, my mum has been saying I'm getting too concerned about the death of Princess Diana. I talk about it too much ... it's always on my mind"... She told me she had been selfharming for a couple of years and she tried me out for 3 or 4 months before I found out about the selfharm.' (06; M; 40-49; P)

\section{A 'duty of care'}

I think with young people that's even more important, ... I just have this fear with young people that if one person fails to listen that could be the end of it all and so if they need 30 minutes that's absolutely fine, whereas if I spent 30 minutes with an adult I might feel a little bit more as though that wasn't such a good use of my time perhaps ...' (08; F; 30-39; S)

\section{Box 6. GPs' preferred epistemological framework}

\section{Biomedical perspective}

If it's truly depression then it's not really different (between younger and older patients). I think there will be biological depression that has started early... . If I think its depression I think it's the same illness, but perhaps sometime harder to tell whether it is depression or not in young people. ' $(01 ; \mathrm{F} ; 50-59 ; \mathrm{S})$

oh what's the word I am looking for, just sort of almost acceptable hopelessness that a lot of teenagers have or go through they would call them Emos wouldn't they? And there is always, every class has a section of emos, and how many of these people are clinically depressed? Or you know, to quote a phrase, going through a phase, you know so it's trying to make sure that you are not catching a few of them in the net when maybe it's just a sort of reactive phase that they are going through and not true depression ... ' $(15 ; \mathrm{M}$; 40-49; PI

\section{Biographical-biological perspective}

she doesn't need medication, she doesn't need to keep seeing to doctors in a way, she just needs loads and loads of social support really, and someone to help her through it really because she hasn't got that social network to do it really.' (03; F; 50-59; P)

and you've got dad who is violent with the partner, yeah. But that often comes out when you do your genogram, I mean I will often go away if it's complex case I will get out all the notes you know look at mam's notes, and realise oh gosh she had mental health problems and she was a school refuser and so it's about a big jigsaw... So I take pride in my letters to CAMHS, so you know I have been known to send them genograms. And that is because I know the families so well.' (10; $M ; 40-49 ; \mathrm{P})$

\section{Interpretative perspective}

and I am becoming more and more a believer in narrative medicine, that none of it actually exists, it's a story and it's an evolving story and I think if that evolving story can have a better ending then it's always a good thing. And I think it's very important how I end it when people leave the room.' $106 ; \mathrm{M} ; 40-49 ; \mathrm{P})$

'I don't think they have got a chemical imbalance ... I suppose my belief is you now, when you see young people with distress, its often trauma based, relationship based. ' $(10 ; \mathrm{M} ; 40-49 ; \mathrm{P})$

of a definable and diagnosable disorders amenable to treatment (Box 6, 01; F; 50-59; S). Where they were unable to discern a discrete mental health difficulty they were inclined to dismiss signs of distress as not a medical problem' and disengage.

Doctors using a biographical-biological perspective considered psychological difficulties in adolescence as largely psychosocial in origin. They recognised the role of the family and drew on family history as important social information (Box 6, 03; F; 50-59; P). Those practitioners whose accounts resonated with an interpretative paradigm demonstrated a view that stories of conflict, anger, social withdrawal, sadness could not be distilled to a single 'truth' and acknowledged that uncertainty and complexity are fundamental to the human condition (Box 6, 06; M; 40-49; P). This was not to deny a biological reality, or refute risk but to see the role of the GP as codesigner of the story.

\section{DISCUSSION}

\section{Summary}

Managing young people who present in surgery with psychological difficulties can be a complex clinical practice. The participants collectively described a sense of their professional competence being challenged yet reacted with varying degrees of engagement. Three themes appeared to shape a GP's response: performance in the clinical encounter; view of adolescents and their health needs; and the GP's own preferred epistemological framework.

A GP's behaviour in the consultation, which can encourage or inhibit an exploration of psychological problems, included a doctor's capacity to deal with a three-way consultation. Although not unique to adolescents, triadic consultations raise particular concerns with this age group because often the teenager is silent and it is the parent and GP who converse.

Seeing adolescents as occupying a separate social group, rather than patients on a life journey, was shown to distance the GPs from any meaningful involvement and lead to a prompt referral to secondary care.

A GP's preferred epistemological framework shapes attitudes, as well as defining how psychological difficulties are understood, and led to varying patterns of engagement. Seeing psychological problems as indicative of definable disorders, resulted in less engagement with the individual; in contrast to seeing psychosocial stress as the root cause which triggered further exploration with the young person as to what was happening in their life. For those in the interpretive paradigm, psychological problems need to be disentangled and examined with the young person, mindful of external (societal) pressures which can undermine adolescent wellbeing.

How these three themes tri-directionally influence each other is explored in the third and final stage of analysis reported in the companion article in this issue. ${ }^{21}$

\section{Strengths and limitations}

Qualitative methodology allows unexplored areas to be examined from multiple perspectives. Theoretical sampling allows for emerging ideas to be tested and either 
reinforced or abandoned; such as the early theme that younger and female GPs might engage more with teenagers, which was later unsupported by the data. Having three researchers from different disciplinary backgrounds enriched the analysis. The data is derived from unobserved accounts and would be augmented by observational data, which can be problematic to gather in reality. Further triangulation of the data with other types of data might support or challenge the themes presented; for example investigating young people's responses to the findings would offer greater insight regarding the robustness and generalisability of the results.

Theoretical sampling did not lead to identifying GPs from cultural minority groups, although cultural perspectives need to be examined.

\section{Comparison with existing literature}

This study contributes to a small but growing body of work examining how GPs respond to adolescent psychological difficulties. GPs do not rate their competence in this area highly ${ }^{12,13}$ and are reluctant to initiate probing conversations. ${ }^{14}$ Anxiety and uncertainty about practice were the first level lopen codingl findings of this reported study. ${ }^{17}$ When faced with adult patients presenting with psychological problems GPs have been shown to respond to uncertainty with a diagnosis of depression and medication. ${ }^{22}$ When faced with adolescent patients Illiffe and colleagues conclude that GPs view adolescents as 'qualitatively different', and are wary of medicalising distress. ${ }^{15}$

Where GPs could acknowledge the emotional distress associated with psychological problems they were more flexible, both in their performance in the consultation and interpretation of the problem. Emotional distress is not a diagnostic entity used routinely in clinical practice, and in the literature is often conflated with depression ${ }^{23,24}$ yet it can offer a useful framework when considering adolescent difficulties. It reflects the messy reality of consultations where psychological distress may or may not be associated with a diagnosable mental disorder. ${ }^{25,26}$

\section{Implications for research and practice}

Preparing doctors to confidently consult with teenagers, individually and as part of a triadic consultation, is key to promoting better engagement. Medical education across the board needs to include opportunities to practise these skills with input and feedback from young people.

Presenting the science of adolescence to doctors is fundamental to facilitate their understanding of how and why teenagers may behave in ways which are challenging to respond to, exacerbated by time pressures and unclear expected outcomes. Knowing more about the neurobiological development occurring in puberty, and its relationship to earlier brain development will support GPs to recognise the importance of safeguarding in adolescence where vulnerability is not always apparent.

Greater engagement is also promoted by closer working relationships with secondary care colleagues, and understanding how other disciplines work, and this needs to be addressed in medical education. In addition, presenting a knowledge framework which supports GPs to see emotional distress when they hear accounts of psychological difficulties in adolescence will support patterns of greater engagement, and may lead to the earlier identification of common mental health problems before teenagers enter adulthood.
Ethical approval was granted by Hull \& East Riding Local Ethics Committee (REC Reference No: 08/H1304/97).

\section{Provenance}

Freely submitted; externally peer reviewed.

\section{Competing interests}

The authors have declared no competing interests.

\section{Acknowledgements}

The authors thank the GP participants for their time and candour, and their practices for supporting the research. We thank the reviewers for their constructive and insightful comments.

\section{Discuss this article}

Contribute and read comments about this article: www.bjgp.org/letters 


\section{REFERENCES}

1. Patel V, Flisher A, Hetrick S, McGorry P. Mental health of young people: a global public-health challenge. Lancet 2007; 369(9569): 1302-1313.

2. Green H, McGinnity A, Meltzer $\mathrm{H}$, et al. Mental health of children and young people in Great Britain, 2004: summary report. London: Office of National Statistics, 2005.

3. Davies SC. Annual report of the Chief Medical Officer: our children deserve better: prevention pays. London: Department of Health, 2013.

4. World Health Organization. The second decade: improving adolescent health and development. Geneva: WHO, 2001.

5. Kramer T, Garralda M. Child and adolescent mental health problems in primary care. Adv Psych Treat 2000; 6: 287-294.

6. Hickie I, Fogarty A, Davenport T, et al. Responding to experiences of young people with common mental health problems attending Australian general practice. Med J Aust 2007; 187(7 Suppl): S47-S52.

7. Haller Dm, Sanci LA, Sawyer SM, Patton GC. The identification of young people's emotional distress: a study in primary care. Br J Gen Pract 2009; DOI: 10.3399/ bjgp09X419510.

8. Coleman J, Brooks F. Treadgold P. Key data on adolescence. London: Association for Young People's Health, 2011

9. Hagell A, Coleman J, Brooks F. Key data on adolescence. London: Association of Young People's Health, 2013

10. Kessler R, Berglund P. Demler O, et al. Lifetime prevalence and age-of-onse distributions of DSM-IV disorders in the national comorbidity survey replication. Arch Gen Psychiatry 2005; 62(6): 593-602

11. Tait L. To disclose or not to disclose psychological problems to GPs. Br J Gen Pract 2009; 59(566): 638-639.

12. Viet F, Sanci L, A, Young D, Bowes G. Adolescent health care: perspectives of Victorian general practitioners. Med J Aust 1995; 163: 16-18.

13. Cockburn K, Bernard P. Child and adolescent mental health within primary care: a study of general practioner's perceptions. Child Adolescent Men Health 2004; 9(1): $21-24$
14. Martinez R, Reynolds S, Howe A. Factors that influence the detection of psychological problems in adolescents attending general practices. $\mathrm{Br} \mathrm{J} \mathrm{Gen}$ Pract 2006; 56(529): 594-599.

15. Illiffe S, Williams G, Fernandez V, et al. General practitioners' understanding of depression in young people: qualitative study. Prim Health Care Res Dev 2008; 9(4): 269-279.

16. Illiffe S, Gallant C, Kramer T, et al. Therapeutic identification of depression in young people: lessons from the introduction of a new technique in general practice. Br J Gen Pract 2012; DOI: 10.3399/bjgp12X630061.

17. Roberts JH, Crosland A, Fulton J. "I think this is maybe our Achilles heel... exploring GPs' responses to young people presenting with emotional distress in general practice: a qualitative study. BMJ Open 2013; 3(9): e002927.

18. Glaser B, Strauss A. The discovery of grounded theory: strategies for qualitative research. Chicago, IL: Aldine, 1967.

19. Charmaz K. Constructing grounded theory: a practical guide through qualitative analysis. London: Sage Publications, 2006.

20. Clarke A. Situational analysis: grounded theory after the postmodern turn. Thousand Oaks, CA: Sage Publications, Inc, 2005

21. Roberts J, Crossland A, Fulton J. GPs' responses to adolescents presenting with psychological difficulties: a conceptual model of fixers, future planners, and collaborators. Br J Gen Pract 2014; DOI: 10.3399/bjgp14X679679.

22. Dowrick C, Gask L, Perry R, et al. Do general practitioners' attitudes towards depression predict their clinical behaviour? Psychol Med 2000; 30(2): 413-419.

23. Zuckerbrot RA, Jensen PS. Improving recognition of adolescent depression in primary care. Arch Pediatr Adolesc Med 2006; 160(7): 694-704.

24. Ozer EM, Zahnd EG, Adams SH, et al. Are adolescents being screened for emotional distress in primary care? J Adolesc Health 2009; 44(6): 520-527.

25. Mendive J. Emotional distress: an alternative primary care perspective. Ment Health Fam Med 2009; 6: 125-127.

26. Dowrick C, Frances A. Medicalising unhappiness: new classification of depression risks more patients being put on drug treatment from which they wil not benefit. BMJ 2013; 347: f7140. 


\section{Appendix 1. Early topic guide}

Focused on five broad areas, derived from the literature available at the time, to promote open discussion

1. I'd like to talk about your experiences of consulting with young people in general

- How do you find this age group (12-19 year olds)?

- Is it very different to consulting with older patients?

- What sort of problems do you see? Do they consult often?

2. Can we talk more about consulting with younger patients who may have psychological/mental health problems?

- How do you find this clinical area?

- What about seeing teenagers alone/with 'another'?

- Any areas particularly tricky to broach?

3. How do you consider possible 'mental health problems' in adolescence?

- Do any examples come to mind?

- What approach did you take?

- What worked well? What was difficult?

- Is it different with other age groups?

- Who else might be involved?

4. What are your thoughts on 'depression' and 'anxiety' in young people?

- Do you see much of it?

- Does this differ from other age groups?

- What options are there in primary care?

- What do you tend to do?

5. Do you think GPs have a role/or not in addressing/promoting emotional wellbeing in young people? Explore. Subsequent refinement of topic guide included asking in addition about factors external to the consulting room. How do they impact? 